\title{
Time trends in adolescent mental well-being in Czechia between 2002 and 2018: Gender, age and socio-economic differences
}

\section{Alina Cosma ( $\square$ alina.cosma@hbsc.org )}

Univerzita Palackeho v Olomouci Fakulta telesne kultury https://orcid.org/0000-0002-0603-5226

\section{András Költő}

National University of Ireland Galway

Petr Badura

Univerzita Palackeho v Olomouci Fakulta telesne kultury

\section{Petr Winkler}

Narodni ustav dusevniho zdravi

\section{Michal Kalman}

Univerzita Palackeho v Olomouci Fakulta telesne kultury

\section{Research article}

Keywords: Adolescence; mental health; mental well-being; well-being; gender; trends; age; socio-economic status; HBSC

Posted Date: March 10th, 2020

DOI: https://doi.org/10.21203/rs.3.rs-16573/v1

License: (c) (i) This work is licensed under a Creative Commons Attribution 4.0 International License. Read Full License 


\section{Abstract}

Background: Recent literature points to a decline over time in adolescent mental well-being but results are inconsistent and rely mainly on data from Western societies. This study investigates time trends in adolescent mental well-being (psychological and somatic complaints, life satisfaction) among Czech adolescents and explores whether these time trends are moderated by gender, age and socio-economic status. Methods: Nationally representative data from 29,378 Czech adolescents $(50.8 \%$ girls, $\mathrm{M}$ age $=$ 13.43; SD age $=1.65$ ) across five Health Behaviour in School-aged Children (HBSC) surveys $(2002,2006$, 2010,2014 , and 2018) were included in the analyses. Hierarchical regression models estimated national trends in adolescent mental well-being. We also tested whether these trends vary between girls and boys, adolescents of different age and from different socio-economic backgrounds. Results: Across the quadrennial surveys from 2002 to 2018, an increase in the psychological complaints was observed. Life satisfaction decreased over time up to 2014 only, whereas somatic symptoms increased until 2010, followed by a decline in 2014 and 2018. Girls, older adolescents and those from low family affluence reported poorer mental well-being outcomes. Gender gap increased over time for psychological complaints and life satisfaction. Socio-economic inequalities gap in adolescent mental well-being remained stable over the investigated timeframe. Conclusions: Our findings do not provide evidence for substantial temporal changes in mental well-being among adolescents in Czechia. Yet, only the increase in psychological complaints has been consistent which is an indicator of a decline over time in adolescent mental well-being. Furthermore, the gender gap in reporting psychological complaints and life satisfaction increased over time, whereas the age and socio-economic differences remained relatively stable. This calls for the attention of public health professionals and policy makers from Czechia. Keywords: Adolescence; mental health; mental well-being; well-being; gender; trends; age; socio-economic status; HBSC

\section{Background}

Adolescence is a highly formative life stage for the individual's future health and well-being [1]. Therefore, it is crucial to investigate the changes happening in this life stage and support young people have happy and balanced lives, prevented from health risks. Many adult mental health problems have their onset in childhood and adolescence [2] leading to adolescent mental health to be seen as a global and national public health priority $[3,4]$. Previous literature has defined adolescent mental health as an overarching, multi-faceted, concept that includes both mental health problems and the presence of subjective wellbeing. In the present paper, we focus on the latter aspect, which we refer to as mental well-being. Nowadays, adolescents report lower levels of well-being and more mental health problems than their peers one or two decades ago $[5,6]$. Furthermore, there is a lack of systematic evidence on trends in adolescent mental well-being from Central and Eastern European countries. Therefore, this study seeks to fill in this data and knowledge gap by exploring recent trends (2002 to 2018) in mental well-being in nationally representative cohorts of 11-, 13- and 15-year-old adolescents from Czechia.

\subsection{Trends in adolescent well-being and mental health}


There is evidence pointing to a deterioration in the mental well-being of children and adolescents in developed countries [6, 7]. However, the findings reporting trends in adolescent mental well-being are rather mixed. A considerable number of studies found increasing time trends in mental health problems, especially internalizing problems, among adolescents in many Western countries including United Kingdom [8-10]; Norway [11, 12]; Scotland [13]; Sweden [14, 15]; or Finland [16]. However, other studies exploring trends in adolescent mental well-being found rather a stable [17] or a decreasing trend [18] while others demonstrated either increase or decrease in mental well-being [19]. To illustrate, a recent investigation in Finland found an increase in the incidence of internalizing symptoms, but only among girls [16]. However, other studies in the United Kingdom, covering a similar time frame, report some stability or even an improvement in mental health overall [20,21]. These inconsistent findings may be attributed to the variation in survey methodologies employed (i.e., the conceptualization of the outcomes, number of assessment points, the length of the investigated time frame, or characteristics of the sample as the age of the respondents).

The majority of the studies on trends in adolescent mental well-being have been conducted in mostly western societies, and their findings might not necessarily be generalizable to other countries or cultures (i.e. Central or Eastern Europe). Furthermore, only a limited number of studies have explored these changes over time in adolescent mental well-being in Central-Eastern European countries (e.g. Poland, [22]). This could be particularly of interest given that among adults, the transition of Central and Eastern European countries from communism to capitalism in the 1990s and the subsequent decade was reflected by a decrease and then a recovery in life satisfaction [23], which might have an impact on those age cohorts who are the parents of nowadays' adolescents. These transitions could have impacted the changes over time in mental well-being, and indirectly may impact the health of contemporary young people.

\subsection{Gender, age, and socio-economic differences in the trends in adolescent well-being}

Consistent gender age and socio-economic differences in adolescent mental well-being trends were reported (e.g. [5]). Time trends analyses showed that compared to boys, girls are reporting increasingly more emotional problems [8]; internalizing problems [5], lower life satisfaction and more multiple health complaints [24]. Studies using longitudinal [25] or cross-sectional data [16] have found similar patterns. Furthermore, a progressive decrease in mental well-being from early to late adolescence has been observed across different cohorts [26], and these declines in well-being and the increase in internalizing problems over time were particularly stronger in older adolescent girls [5]. Self-rating of health in adolescents was consistently found to worsen with age, and girls showed a sharper decline than boys $[27,28]$. The authors link these age patterns to puberty and its related neuro-hormonal changes. In addition, older adolescents may experience a growing number of stressful life events [29], for instance transitioning to high school [30,31], cumulative victimisation [32], or events related to family or romantic relationships [33], which may have an increasingly negative impact on their mental health and well-being. In our study we would expect a stronger decline over time in mental well-being for older adolescent girls. 
Socioeconomic inequalities have a large impact on adolescent mental well-being [34]. Compared to their peers from more affluent families, adolescents from socially disadvantaged groups have higher rates of poor subjective health [35], lower life satisfaction and higher load of multiple health symptoms [36], and lower quality of life and well-being [37]. Whereas previous literature indicates that there has been an increase over time in the social inequalities in adolescent mental health [38], there is also support for a rather constant trend in the time frame 1994 to 2010 [39]. Therefore, exploring social economic inequalities in adolescent mental well-being in a country like Czechia - that has experienced significant economic growth in the last decades - could bring more clarity into this topic.

\subsection{Aims and research questions of the current study}

In sum, while many studies have reported recent declines in adolescent mental well-being, the literature stems mostly from Western European and North American countries, and it is limited in terms of the comparability of time periods examined, methods used, countries studied, and outcomes measured. The present study addresses these challenges by using national representative data from Czech adolescents from 2002 to 2018. In this investigation, we aim to address the following research questions (RQ):

To what extent have adolescent mental well-being indicators (life satisfaction, psychological and somatic symptoms) changed in Czechia between 2002 and 2018?

Do these trends vary between girls and boys, adolescents of different age and from different socioeconomic backgrounds?

\section{Methods}

\subsection{Study Design}

Data were drawn from the Czech Health Behaviour in School-Aged Children (HBSC) study. The HBSC is a World Health Organization collaborative cross-national study that has been conducted every four years to monitor the health and well-being of adolescents using a standardized research protocol [40]. Since the study was established in 1983, fifty countries in Europe and North America have joined the survey. For each survey round, the participating countries collect data from a nationally representative sample of 11-, 13- and 15-year-olds using a standardized research protocol. Stratified random cluster sampling is employed with classes within schools as the primary sampling units. Adolescents complete anonymous questionnaires in classroom settings. Questionnaires were translated from English into Czech with backtranslation checks, following a validated protocol [40].

\subsection{Participants and data collection}

This study used data from five Czech HBSC survey cycles (2002, 2006, 2010, 2014, and 2018). Nationally representative sample of 11-, 13- and 15-year-olds were included in each survey cycle: $2002(\mathrm{~N}=4,855$; $52 \%$ girls), 2006 ( $N=4,597 ; 49,5 \%$ girls), 2010 ( $N=4,152 ; 51,5 \%$ girls), 2014 ( $N=4,834 ; 52.4 \%$ girls), and $2018(\mathrm{~N}=10,938$ (51\% girls), respectively, resulting in a total sample of 29,378 adolescents (Table 1$)$. 
Table 1

Sample characteristics $(N=29,376)$

\begin{tabular}{|c|c|c|c|c|c|c|}
\hline & 2002 & 2006 & 2010 & 2014 & 2018 & Total \\
\hline Participants per survey & 4,855 & 4,597 & 4,152 & 4,834 & 10,938 & 29,376 \\
\hline \multicolumn{7}{|l|}{ Gender } \\
\hline Boys (\%) & 48.1 & 50.5 & 48.5 & 47.6 & 50.1 & 49.2 \\
\hline Girls (\%) & 51.9 & 49.5 & 51.5 & 52.4 & 49.8 & 50.8 \\
\hline Mean age $(S D)^{a}$ & $\begin{array}{l}13.43 \\
(1.65)\end{array}$ & $\begin{array}{l}13.51 \\
(1.64)\end{array}$ & $\begin{array}{l}13.49 \\
(1.66)\end{array}$ & $\begin{array}{l}13.44 \\
(1.65)\end{array}$ & $\begin{array}{l}13.36 \\
(1.65)\end{array}$ & $\begin{array}{l}13.43 \\
(1.65)\end{array}$ \\
\hline $\begin{array}{l}\text { Mean family affluence } \\
(S D)^{b}\end{array}$ & $\begin{array}{l}4.09 \\
(1.69)\end{array}$ & $\begin{array}{l}4.66 \\
(1.85)\end{array}$ & $\begin{array}{l}5.51 \\
(1.87)\end{array}$ & $\begin{array}{l}5.55 \\
(1.85)\end{array}$ & $\begin{array}{l}5.96 \\
(1.89)\end{array}$ & $\begin{array}{l}5.32 \\
(1.97)\end{array}$ \\
\hline \multicolumn{7}{|l|}{$\begin{array}{l}\text { Mental health and well- } \\
\text { being }\end{array}$} \\
\hline Mean life satisfaction $(S D)^{c}$ & $\begin{array}{l}7.45 \\
(1.88)\end{array}$ & $\begin{array}{l}7.28 \\
(1.88)\end{array}$ & $\begin{array}{l}7.51 \\
(1.83)\end{array}$ & $\begin{array}{l}7.20 \\
(2.01)\end{array}$ & $\begin{array}{l}7.79 \\
(1.74)\end{array}$ & $\begin{array}{l}7.52 \\
(1.86)\end{array}$ \\
\hline $\begin{array}{l}\text { Mean psychological } \\
\text { symptoms }(S D)^{d}\end{array}$ & $\begin{array}{l}1.30 \\
(0.87)\end{array}$ & $\begin{array}{l}1.40 \\
(0.97)\end{array}$ & $\begin{array}{l}1.44 \\
(1.01)\end{array}$ & $\begin{array}{l}1.36 \\
(1.01)\end{array}$ & $\begin{array}{l}1.42 \\
(0.98)\end{array}$ & $\begin{array}{l}1.39 \\
(0.96)\end{array}$ \\
\hline $\begin{array}{l}\text { Mean somatic } \\
\text { symptoms(SD) }\end{array}$ & $\begin{array}{l}0.73 \\
(0.71)\end{array}$ & $\begin{array}{l}0.83 \\
(0.74)\end{array}$ & $\begin{array}{l}0.92 \\
(0.74)\end{array}$ & $\begin{array}{l}0.70 \\
(0.74)\end{array}$ & $\begin{array}{l}0.69 \\
(0.72)\end{array}$ & $\begin{array}{l}0.76 \\
(0.74)\end{array}$ \\
\hline
\end{tabular}

Over the study period, the response rate at the level of pupils ranged between $86 \%$ (2010) and $90 \%$ (2018) [41]. Data were collected by trained research assistants. All the surveys prior to 2018 employed a paper and pencil data collection, while in 2018 the data was collected using an online survey. No substantial differences in the results of the HBSC survey across paper-based and electronic administration have been reported [42]. The participants were assured of the anonymity and confidentiality of their responses.

\subsection{Instruments}

Psychological and somatic symptoms. The HBSC Symptom Checklist, a non-clinical measure used to asses two different types of health symptoms: psychological (feeling low, irritability or a bad mood, feeling nervous and sleeping difficulties) and somatic (headache, stomach-ache, backache and dizziness) symptoms [43]. Participants had to indicate how often they experienced these symptoms over the last six months. Response categories were: "about every day", "more than once a week", "about every week", "about every month" and "rarely or never". This instrument has adequate test-retest reliability and validity properties [28]. In our sample, both these subscales had acceptable reliability ( $\alpha=0.74$ for psychological symptoms; $a=0.63$ for somatic symptoms). Items were reverse coded, and for each sub- 
scale, a mean score (0-4) was created which was used in the subsequent analyses, with a higher score indicating more frequent incidence of the symptoms.

Life satisfaction was assessed with the Cantril ladder [44]. Participants rated how happy do they feel about their life on a visual analogous scale ranging from the worst possible life (0) to the best possible life (10). This instrument is a well-validated measure of adolescent well-being [45]. For this study, the scale was used as a continuous variable.

Gender and age. Respondents were asked to indicate whether they are a boy or a girl, as well as to report their date of birth (month/year).

Socioeconomic status was measured by the Family Affluence Scale (FAS), a 4-item composite measure developed by the HBSC network [46]. FAS measures material family wealth as an indicator of socioeconomic position. It asks about real possessions (i.e., number of family cars; computers), characteristics of the home (i.e., having a bedroom for one own), and the number of family holidays in the last year. The scores are summed up ( $0=$ lowest affluence, $9=$ highest affluence), and this score was used in the subsequent analyses.

\subsection{Statistical analysis}

To examine to what extent the mental well-being indicators have changed over time (2002 to 2018), the means were calculated per survey year for the total sample, and each gender separately. To test trends in adolescent mental well-being, multiple regression analyses were conducted, using the year 2002 as the reference year and the other survey years were added as dummies (Model 1) while controlling for gender, age and family affluence. To investigate the extent to which trends in well-being have been different for girls and boys, we added the survey year $\times$ gender interaction term in the model (Model 2). Subsequently, we explored if the age and the socio-economic differences have changed over time, by introducing survey year $\times$ age interaction term (Model 3 ), and survey year $\times$ family affluence interaction term (Model 4 ), respectively. A final model (Model 5) testing whether the trends have been stronger for older adolescent girls (survey year $\times$ gender $x$ age) was run. All analyses were performed using statistic software package SPSS 24 (IBM Corp. Released 2016. IBM SPSS Statistics for Windows, Version 24.0. Armonk, NY: IBM Corp). Associations and interaction effects were considered significant if $p<.05$.

\section{Results}

The socio-demographic characteristics of the sample are illustrated in Table 1. The average age of the total sample was 13.43 ( $S D=1.65$ ) (mean age range from 13.36 in 2018 to 13.51 in 2006), and 51\% were girls (range from 49.5 in 2006 to 52.4 in 2014). Across all survey years, apart from life satisfaction in 2002, girls reported significantly higher levels of psychological and somatic symptoms and lower levels of life satisfaction (Table 2). Overall, mean scores for somatic symptoms were lower than for psychological symptoms. 
Table 2

Marginal estimated means for life satisfaction and health symptoms by gender $(N=29,376)$

\begin{tabular}{|c|c|c|c|c|c|}
\hline & 2002 & 2006 & 2010 & 2014 & 2018 \\
\hline & $\begin{array}{l}\text { Mean }(95 \% \\
\mathrm{Cl})^{a}\end{array}$ & $\begin{array}{l}\text { Mean }(95 \% \\
\mathrm{Cl})^{\mathrm{a}}\end{array}$ & $\begin{array}{l}\text { Mean }(95 \% \\
\mathrm{Cl})^{\mathrm{a}}\end{array}$ & $\begin{array}{l}\text { Mean }(95 \% \\
\mathrm{Cl})^{\mathrm{a}}\end{array}$ & $\begin{array}{l}\text { Mean }(95 \% \\
\mathrm{Cl})^{\mathrm{a}}\end{array}$ \\
\hline \multicolumn{6}{|l|}{ Boys } \\
\hline $\begin{array}{l}\text { Mean life satisfaction } \\
(S D)^{c}\end{array}$ & $\begin{array}{l}7.67 \\
(7.60- \\
7.75)\end{array}$ & $\begin{array}{l}7.55(7.48- \\
7.63)\end{array}$ & $\begin{array}{l}7.60 \\
(7.53- \\
7.68)\end{array}$ & $\begin{array}{l}7.27 \\
(7.20- \\
7.34)\end{array}$ & $\begin{array}{l}7.78(7.73- \\
7.82)\end{array}$ \\
\hline 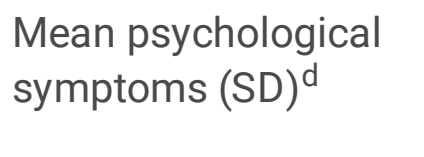 & $\begin{array}{l}1.16 \\
(1.12- \\
1.20)\end{array}$ & $\begin{array}{l}1.22(1.18- \\
1.26)\end{array}$ & $\begin{array}{l}1.28 \\
(1.24- \\
1.32)\end{array}$ & $\begin{array}{l}1.19 \\
(1.15- \\
1.23)\end{array}$ & $\begin{array}{l}1.27(1.24- \\
1.29)\end{array}$ \\
\hline $\begin{array}{l}\text { Mean somatic } \\
\text { symptoms }(S D)^{d}\end{array}$ & $\begin{array}{l}0.63 \\
(0.60- \\
0.66)\end{array}$ & $\begin{array}{l}0.66(0.60 \\
-0.72)\end{array}$ & $\begin{array}{l}0.80 \\
(0.77- \\
0.83)\end{array}$ & $\begin{array}{l}0.56 \\
(0.54- \\
0.59)\end{array}$ & $\begin{array}{l}0.58(0.57- \\
0.60)\end{array}$ \\
\hline \multicolumn{6}{|l|}{ Girls } \\
\hline $\begin{array}{l}\text { Mean life satisfaction } \\
(S D)^{c}\end{array}$ & $\begin{array}{l}7.58 \\
(7.50- \\
7.65)\end{array}$ & $\begin{array}{l}7.23(7.16- \\
7.31)\end{array}$ & $\begin{array}{l}7.39 \\
(7.32- \\
7.47)\end{array}$ & $\begin{array}{l}7.10 \\
(7.03- \\
7.18)\end{array}$ & $\begin{array}{l}7.59(7.54- \\
7.63)\end{array}$ \\
\hline $\begin{array}{l}\text { Mean psychological } \\
\text { symptoms }(S D)^{d}\end{array}$ & $\begin{array}{l}1.43 \\
(1.39- \\
1.47)\end{array}$ & $\begin{array}{l}1.57(1.53- \\
1.61)\end{array}$ & $\begin{array}{l}1.60 \\
(1.56- \\
1.64)\end{array}$ & $\begin{array}{l}1.53 \\
(1.49- \\
1.57)\end{array}$ & $\begin{array}{l}1.61(1.58- \\
1.63)\end{array}$ \\
\hline $\begin{array}{l}\text { Mean somatic } \\
\text { symptoms(SD) }\end{array}$ & $\begin{array}{l}0.83 \\
(0.80- \\
0.86)\end{array}$ & $\begin{array}{l}0.98(0.95- \\
1.01)\end{array}$ & $\begin{array}{l}1.03 \\
(1.00- \\
1.06)\end{array}$ & $\begin{array}{l}0.84 \\
(0.81-.87)\end{array}$ & $\begin{array}{l}079(0.76- \\
0.81)\end{array}$ \\
\hline
\end{tabular}

\subsection{Trends in Czech adolescent mental well-being}

Changes over time were recorded for all three well-being indicators, but these showed different trajectories. Compared to 2002, life satisfaction significantly decreased in $2006(B=-.235 ; p<.001)$, $2010(B=-.131 ; p<.001)$, and $2014(B=-.440 ; p<.001)$, but it increased in 2018 to levels similar to those in 2002 ( $B=.050 ; p<n s)$. Psychological symptoms, compared to 2002, increased over time, with the largest difference being observed in $2006(B=.149 ; p<.001)$, and $2018(B=.147 ; p<.001)$. In contrast, somatic complaints increased in the interval 2002 to $2010(B=.187 ; p<.001)$, and subsequently declined in 2014 ( $B=-.027 ; p<n s)$, and further in $2018(B=-.044 ; p<.001)$. Compared to 2002, only the decline in somatic complaints observed in 2014 did not significantly differ (Table 3, Model 1). 
Table 3

Time trends in life satisfaction and psychological and somatic symptoms: Interaction effects with gender, age and family affluence $(\mathrm{N}=29,376)$

\begin{tabular}{|c|c|c|c|c|c|c|c|}
\hline \multirow[b]{2}{*}{$\begin{array}{l}\text { Main } \\
\text { effects }\end{array}$} & & \multicolumn{2}{|c|}{ Life satisfaction } & \multicolumn{2}{|c|}{$\begin{array}{l}\text { Psychological } \\
\text { symptoms }\end{array}$} & \multicolumn{2}{|l|}{$\begin{array}{l}\text { Somatic } \\
\text { symptoms }\end{array}$} \\
\hline & & B & SE & B & SE & B & SE \\
\hline \multirow[t]{7}{*}{ Model 1} & $\begin{array}{l}2006 \text { (ref. } \\
2002 \text { ) }\end{array}$ & $-0.235^{\star \star \star}$ & 0.03 & $0.103^{\star \star \star}$ & 0.02 & $0.106^{\star \star \star}$ & 0.06 \\
\hline & $\begin{array}{l}2010 \text { (ref. } \\
2002 \text { ) }\end{array}$ & $-0.131^{\star \star \star}$ & 0.03 & $0.149^{\star \star \star}$ & 0.02 & $0.187^{\star \star \star}$ & 0.01 \\
\hline & $\begin{array}{l}2014 \text { (ref. } \\
2002 \text { ) }\end{array}$ & $-0.440^{\star \star \star}$ & 0.03 & $0.072^{\star \star \star}$ & 0.01 & -0.027 & 0.01 \\
\hline & $\begin{array}{l}2018 \text { (ref. } \\
2002)\end{array}$ & 0.050 & 0.03 & $0.147^{\star \star}$ & 0.01 & $-0.044^{\star \star \star}$ & 0.01 \\
\hline & $\begin{array}{l}\text { Gender (ref. } \\
\text { boys) }\end{array}$ & $-0.177^{\star \star}$ & 0.02 & $0.329^{\star \star}$ & 0.01 & $0.237^{\star \star}$ & 0.01 \\
\hline & $\begin{array}{l}\text { Age } \\
\text { (continuous) }\end{array}$ & $-0.159^{\star \star}$ & 0.01 & $0.06^{* * *}$ & 0.01 & $0.048^{\star \star \star}$ & 0.01 \\
\hline & FAS sum & $0.138^{\star *}$ & 0.01 & $-0.011^{\star \star \star}$ & 0.01 & 0.001 & 0.01 \\
\hline \multicolumn{8}{|c|}{$\begin{array}{l}\text { Interaction } \\
\text { effects }\end{array}$} \\
\hline \multirow[t]{4}{*}{ Model 2} & $\begin{array}{l}2006 \times \\
\text { gender }\end{array}$ & $-0.248^{\star \star \star}$ & 0.07 & $0.084^{*}$ & 0.03 & $0.101^{\star * \star}$ & 0.03 \\
\hline & $\begin{array}{l}2010 \times \\
\text { gender }\end{array}$ & $-0.156^{*}$ & 0.07 & 0.070 & 0.03 & 0.046 & 0.03 \\
\hline & $\begin{array}{l}2014 \times \\
\text { gender }\end{array}$ & -0.110 & 0.07 & $0.081^{*}$ & 0.03 & $0.093^{\star \star \star}$ & 0.03 \\
\hline & $\begin{array}{l}2018 x \\
\text { gender }\end{array}$ & $-0.131^{*}$ & .06 & $0.085^{\star \star}$ & 0.03 & 0.015 & 0.02 \\
\hline \multirow[t]{3}{*}{ Model 3} & $2006 \times$ age & $0.075^{\star \star \star}$ & 0.02 & 0.014 & 0.01 & -0.16 & 0.01 \\
\hline & $2010 \times$ age & 0.036 & 0.02 & $0.035^{\star *}$ & 0.01 & 0.017 & 0.01 \\
\hline & $2014 \times$ age & 0.027 & 0.02 & $0.026^{*}$ & 0.01 & 0.006 & 0.01 \\
\hline
\end{tabular}

${ }^{* * *} p<0.001 ;{ }^{* *} p<0.01 ;{ }^{*} p<0.05$; Models 2,3 and 4 are controlled for main effects of survey year, gender, age, and family affluence, respectively. FAS = Family Affluence Scale 


\begin{tabular}{|c|c|c|c|c|c|c|c|}
\hline & \multirow[b]{2}{*}{$2018 \times$ age } & \multicolumn{2}{|c|}{ Life satisfaction } & \multicolumn{2}{|c|}{$\begin{array}{l}\text { Psychological } \\
\text { symptoms }\end{array}$} & \multicolumn{2}{|c|}{$\begin{array}{l}\text { Somatic } \\
\text { symptoms }\end{array}$} \\
\hline & & -0.034 & 0.02 & $0.034^{\star \star \star}$ & 0.01 & -0.005 & 0.01 \\
\hline \multirow[t]{4}{*}{ Model 4} & $2006 \times$ FAS & -0.030 & 0.02 & 0.001 & 0.01 & 0.011 & 0.008 \\
\hline & $2010 \times$ FAS & -0.005 & 0.02 & 0.009 & 0.01 & 0.007 & 0.008 \\
\hline & $2014 \times$ FAS & -0.025 & 0.02 & 0.013 & 0.01 & 0.014 & 0.008 \\
\hline & $2018 \times$ FAS & $-0.060^{\star \star \star}$ & 0.02 & 0.004 & $0.00 ` 9$ & 0.007 & 0.007 \\
\hline
\end{tabular}

\subsection{Gender, age, and socio-economic differences in the trends in adolescent well-being}

Compared to boys, girls reported lower life satisfaction $(B=-.177 ; p<.001)$, and more psychological ( $B$ $=.329 ; p<.001)$ and somatic symptoms $(B=.237 ; p<.001)$. Nonetheless, even if these gender differences have increased over time, they were not consistent across the mental well-being indicators. To illustrate, compared to 2002, the gap between boys and girls in reporting life satisfaction increased over time in all survey years, except of 2014. On the other hand, the differences between boys and girls in reporting psychological symptoms compared to 2002 increased over time in all years, except in 2010. Furthermore, these gender differences in reporting somatic symptoms increased only in $2006(B=.101 ; p<.001)$ and $2014(B=.093 ; p<.001)$. Three-way interaction analyses were run (survey year $\times$ gender $\times x$ age - results not illustrated in Table 2), which confirmed that the increase in psychological complaints have been stronger for older adolescent girls in $2006(B=.066 ; p<.001)$, in $2014(B=.040 ; p<.05)$ and in $2018(B$ $=.066 ; \mathrm{p}<.001)($ Fig. 1a-c).

Overall, with increasing age, adolescents in Czechia reported lower levels of life satisfaction $(B=-.159 ; p$ $<.001)$ and higher levels of psychological $(B=.06 ; p<.001)$ and somatic symptoms $(B=.048 ; p<.001)$. Nonetheless, the differences between younger and older adolescents have increased over time only for psychological symptoms (Table 3, Model 3). For life satisfaction and somatic symptoms, the age gap remained stable in the investigated time frame except 2006, when the age differences increased for life satisfaction $(B=.075 ; p<.001)$.

Higher family affluence was associated with higher levels of life satisfaction $(B=.138 ; p<.001)$ and less frequent psychological symptoms $(B=-.011 ; p<.001)$. No associations between family affluence and somatic symptoms were found. These socio-economic differences remained stable over time, except for life satisfaction, where family affluence differences decreased in 2018 compared to 2002 ( $B=-.060 ; p$ $<.001)$. 


\section{Discussion}

The current study examined trends in three indicators of adolescent mental well-being using nationally representative cross-sectional data from Czechia (2002, 2006, 2010, 2014 and 2018). Importantly, the study also investigated whether the trends in adolescent mental well-being were moderated by gender, age and family affluence. Our first main finding indicates that in Czechia, the adolescent mental wellbeing has changed between 2002 and 2018 across all three mental well-being indicators, but each indicator had a different pattern of change over time. During this period, a consistent increase in the prevalence of psychological symptoms emerged from 2002 onwards, whereas for life satisfaction a decline was observed up to 2014. From 2014 to 2018, an increase in life satisfaction was observed. For somatic complaints, an increase was observed up to 2010 , followed by a subsequent improvement over time. These findings despite small in size are at odds with other studies that reported rather a stable state of emotional and behavioural symptoms between 2003 and 2013 in the Netherlands [18] or Norway [12].

Nonetheless, the fact that we observed no further deterioration in life satisfaction and somatic complaints is in line with other recent studies that support either a stabilization or further decline of selfreported mental well-being [16, 47]. In an international comparison, adolescents from Czechia and the United States were the only ones whose self-rated health worsened between 2002 and 2006, and then showed an increase from 2006 to 2010 [48]. Our findings are comparable to this pattern and indirectly suggest the presence of potential buffering factors such increase in family support and communication. Future studies should explore this in more depth.

The diverging trends in psychological complaints, somatic complaints and life satisfaction reinforce the idea that adolescent mental well-being is not a unidimensional construct and that its different components of mental well-being can show different trajectories and may have differential susceptibilities. Life satisfaction, which refers to global cognitive evaluations about one's life, can be considered a global construct of subjective well-being, and may therefore be influenced by broader life experiences and relationships [44]. In contrast, psychosomatic complaints may represent symptoms of more immediate stress which, at the more severe end, may impair everyday functioning and could be associated with problems from the internalizing spectrum. Furthermore, emotional components of wellbeing (i.e. psychological complaints) tend to be more prone to fluctuations compared to life satisfaction, which is usually described as a more stable component [49]. Nonetheless, these findings emphasize the need to view mental well-being as a multi-dimensional construct [50] and suggest a need for greater understanding of the associations between risk factors and different aspects of mental well-being.

Adolescent girls reported lower mental well-being compared to boys, but this gender gap has not systematically increased over time. This result confirms that girls are more likely to report poorer mental well-being outcomes [5], and also supports a consistent body of research (e.g. [6]) which found increasing trends in girls only for emotional problems $[8,16]$ or psychological and somatic symptoms $[17,43]$. This increase in gender gap over time could be explained, among others, by the exposure to gender role expectations and the socially defined roles for women and men in society together with exposure to 
gender-specific stressors [51]. Furthermore, there is considerable evidence that girls are expected to be more emotionally sensitive [52], experience more restricted gender roles and body dissatisfaction [53], are more likely to experience and communicate health symptoms [54], or experience more school performance pressure [55], which may all contribute to the gender disparities in mental well-being we observed in adolescents from Czechia.

Similarly to the consistent gender gap, our results indicate that older adolescents were more likely to report low mental well-being and this age gap has increased over time but not across all outcomes. The interaction analyses revealed, though, that these age differences remained stable across the survey years except psychological symptoms where the age gap increased in 2010 and 2018 as compared to 2002 . Nonetheless, including a three-way interaction parameter in the regression model revealed that the increase in psychological complaints had been the strongest among older adolescent girls. This is in line with the results reported by Bor et al.[5].

Furthermore, previous research argued that interaction of mental health outcomes and sociodemographic characteristics as gender, age and socio-economic status showed a large cross-national variability (e.g., [36]), which may explain why the changes in associations over time were less emphasized in Czechia. These results do not follow previous findings which indicated that the decline in mental well-being is slightly stronger for older adolescents compared to younger ones [5, 11]. In Norway, an increasing trend in health complaints among adolescents from 1994 to 2014 was found, especially among older adolescent girls [11]. In Sweden the increase over time in psychological complaints (1985 to 2005) was seen in older adolescents (boys and girls), whereas no significant change was seen in the youngest groups (11-year olds) [14]. Given these mixed results, there is a need for a more comprehensive study which includes more countries over a relatively longer time frame and employs a uniform set of mental health and well-being outcomes for boys, girls, adolescents of different age groups, and socioeconomic backgrounds.

Interestingly, the gap between Czech adolescents coming from different family affluence families remained relatively stable in the investigated time frame. This is in line previous studies that showed that the inequalities in adolescent health complaints in Czechia has been stable from 1994 to 2010 [39], and confirms that this trend has remained stable. This could be partly explained by the demographic characteristics of the Czech population. According to the Gini index [56], Czechia is one of the countries with the lowest income inequality worldwide. In addition, its population is also very homogeneous as regards nationalities of its inhabitants, because only $5 \%$ of them are of non-Czech origin and this has been quite consistent over time [57].

A key strength of the present study is investigating nationally representative samples of adolescents using identical study protocols across a 16-year period. Nonetheless, this inherently fosters the limitation that data collected across time is cross-sectional and self-reported. Secondly, the measures used were restricted to those available in the HBSC study since 2002, therefore providing a relatively limited perspective on adolescent mental health. Further research should include a broader range of mental 
health outcome measures and other potential drivers of mental health trends, such as changes in the school or family environment, or social media use, which are required to better understand this complex issue. Nonetheless, the present study provides essential and up-to-date information about changing mental health trends in early adolescence from the Central European region.

\section{Conclusion}

Based on the present findings, there has been an increase from 2002 to 2018 in psychological health complaints, and a decline in life satisfaction until 2014 among adolescents in Czechia. This decline in adolescent mental health, especially psychological complaints has been stronger among older adolescent girls who were more likely to report higher levels of psychological complaints. These observations suggest that increasing in psychological health complaints should be considered a public health concern in Czechia. It is encouraging that no further decline in life satisfaction and psychosomatic complaints was observed but rather an improvement. To better understand potential determinants of adolescent mental well-being, longitudinal studies and continued tracking of health trends are needed. Besides, school interventions that will assist adolescents in managing psychological and somatic health complaints are vital.

\section{Abbreviations}

HBSC: Health Behaviour in School-aged Children study; Cl: Confidence interval; FAS: Family Affluence Scale; SPSS: Statistical Package for the Social Sciences; WHO: World Health Organization.

\section{Declarations}

\section{Acknowledgements}

The authors thank all the adolescents for participating in each data collection cycle, their parents for agreeing on their participation in the study, and principals and school teachers who helped facilitate the research.

\section{Consent to publication}

Not applicable.

\section{Authors' contributions}

AC conceptualized and designed the study, drafted the initial manuscript, and coordinated the writing of the manuscript. PB and MK prepared the national research protocol survey and participated in the data collection. AC, AK, PB, PW and MK carried out the data analysis and interpreted the results. All the authors read the manuscript, commented on all parts of the text, and approved the final version of the manuscript. 


\section{Funding}

The work was supported by the European Regional Development Fund-Project "Effective Use of Social Research Studies for Practice" (No. CZ.02.1.01/0.0/0.0/16_025/0007294), the Technology Agency of the Czech Republic (ÉTA TL01000335), and by the Ministry of Education, Youth and Sports, Inter-Excellence, LTT18020. The funders had no role in the study design, analysis of the data, decision to publish, or preparation of the study. The funders support nationwide data collection in each cycle of the HBSC crosssectional study.

\section{Availability of data and materials}

The datasets analyzed during the current study are not publicly available because of the rules for funded projects but are available from the corresponding author $\mathrm{AC}$ upon reasonable request. Permission to access and use the data was granted by the Principal Investigator of the Czech HBSC team.

\section{Ethics approval and consent to participate}

The Institutional Research Ethics Committee of the Faculty of Physical Culture, Palacký University Olomouc, approved the design of the study, the course of preparation and execution of the research, an opt-out method for collecting parental consent, and the processing of the data on 4th March 2016, with the reference no. 9/2016. Similar ethical approvals have been granted for the previous surveys as well. The standard procedure across all surveys class was that all the participants, teachers, and school management members received detailed information on the survey design and data collection plan. Detailed information about the survey and its design and content was sent in advance to the parents via the school management. Thereafter, a passive parental consent was employed which implied that the adolescent was permitted to participate in the study unless the parent/guardian indicated that the adolescent should not participate. Adolescents provided written informed consent. They were also assured that the data provided was confidential and anonymous. In each cycle of data collection, the participation of adolescents was voluntary and without any financial incentives.

\section{Competing interests}

The authors declare that they have no conflict of interest.

\section{References}

1. Sawyer SM, Afifi RA, Bearinger LH, Blakemore S-J, Dick B, Ezeh AC, et al. Adolescence: a foundation for future health. Lancet Lond Engl. 2012;379:1630-40. doi:10.1016/S0140-6736(12)60072-5.

2. Kessler RC, Amminger GP, Aguilar-Gaxiola S, Alonso J, Lee S, Ustun TB. Age of onset of mental disorders: A review of recent literature. Curr Opin Psychiatry. 2007;20:359-364.

doi:10.1097/YCO.0b013e32816ebc8c. 
3. Patel V, Flisher AJ, Hetrick S, McGorry P. Mental health of young people: a global public-health challenge. The Lancet. 2007;369:1302-13. doi:10.1016/S0140-6736(07)60368-7.

4. Patel V, Saxena S, Lund C, Thornicroft G, Baingana F, Bolton P, et al. The Lancet Commission on global mental health and sustainable development. Lancet Lond Engl. 2018;392:1553-98. doi: 10.1016/S0140-6736(18)31612-X

5. Bor W, Dean AJ, Najman J, Hayatbakhsh R. Are child and adolescent mental health problems increasing in the 21st century? A systematic review. Aust N Z J Psychiatry. 2014;48:606-616. doi:10.1177/0004867414533834.

6. Collishaw S. Annual Research Review: Secular trends in child and adolescent mental health. J Child Psychol Psychiatry. 2015;56:370-393. doi:10.1111/jcpp.12372.

7. Twenge JM, Joiner TE, Rogers ML, Martin GN. Increases in depressive symptoms, suicide-related outcomes, and suicide rates among U.S. adolescents after 2010 and links to increased new media screen time. Clin Psychol Sci. 2018;6:3-17. doi:10.1177/2167702617723376.

8. Fink E, Patalay P, Sharpe H, Holley S, Deighton J, Wolpert M. Mental Health Difficulties in Early Adolescence: A Comparison of Two Cross-Sectional Studies in England From 2009 to 2014. J Adolesc Health. 2015;56:502-507. doi:10.1016/j.jadohealth.2015.01.023.

9. Patalay P, Gage SH. Changes in millennial adolescent mental health and health-related behaviours over 10 years: a population cohort comparison study. Int J Epidemiol. 2019. doi:10.1093/ije/dyz006.

10. Ross A, Kelly Y, Sacker A. Time trends in mental well-being: the polarisation of young people's psychological distress. Soc Psychiatry Psychiatr Epidemiol. 2017;52:1147-1158. doi:10.1007/s00127-017-1419-4.

11. Potrebny T, Wiium N, Haugstvedt A, Sollesnes R, Torsheim T, Wold B, et al. Health complaints among adolescents in Norway: A twenty-year perspective on trends. PLOS ONE. 2019;14:e0210509. doi:10.1371/journal.pone.0210509.

12. von Soest T, Wichstrøm L. Secular trends in depressive symptoms among Norwegian adolescents from 1992 to 2010. J Abnorm Child Psychol. 2014;42:403-415. doi:10.1007/s10802-013-9785-1.

13. Cosma A, Whitehead R, Neville F, Currie D, Inchley J. Trends in bullying victimization in Scottish adolescents 1994-2014: changing associations with mental well-being. Int J Public Health. 2017;62:639-46. doi:10.1007/s00038-017-0965-6.

14. Hagquist $C$. Discrepant trends in mental health complaints among younger and older adolescents in Sweden: an analysis of WHO data 1985-2005. J Adolesc Health. 2010;46:258-264. doi:10.1016/j.jadohealth.2009.07.003.

15. van Geelen SM, Hagquist C. Are the time trends in adolescent psychosomatic problems related to functional impairment in daily life? A 23-year study among 20,000 15-16 year olds in Sweden. J Psychosom Res. 2016;87:50-56. doi:10.1016/j.jpsychores.2016.06.003.

16. Mishina K, Tiiri E, Lempinen L, Sillanmäki L, Kronström K, Sourander A. Time trends of Finnish adolescents' mental health and use of alcohol and cigarettes from 1998 to 2014. Eur Child Adolesc Psychiatry. 2018;27:1633-1643. doi:10.1007/s00787-018-1158-4. 
17. Potrebny T, Wiium N, Lundegaard MM-I. Temporal trends in adolescents' self-reported psychosomatic health complaints from 1980-2016: A systematic review and meta-analysis. PLoS One. 2017;12:e0188374. doi:10.1371/journal.pone.0188374.

18. Duinhof EL, Stevens GWJM, van Dorsselaer S, Monshouwer K, Vollebergh WAM. Ten-year trends in adolescents' self-reported emotional and behavioral problems in the Netherlands. Eur Child Adolesc Psychiatry. 2015;24:1119-1128. doi:10.1007/s00787-014-0664-2.

19. Whitehead R, Berg C, Cosma A, Gobina I, Keane E, Neville F, et al. Trends in adolescent overweight perception and its association with psychosomatic health 2002-2014: evidence from 33 countries. J Adolesc Health. 2017;60:204-211. doi: 10.1016/j.jadohealth.2016.09.029

20. Gutman LM, Joshi H, Schoon I. Developmental trajectories of conduct problems and cumulative risk from early childhood to adolescence. J Youth Adolesc. 2019;48:181-98. doi:10.1007/s10964-0180971-x.

21. Pitchforth J, Fahy K, Ford T, Wolpert M, Viner RM, Hargreaves DS. Mental health and well-being trends among children and young people in the UK, 1995-2014: analysis of repeated cross-sectional national health surveys. Psychol Med. 2019;49:1275-85.

22. Konowałek $t$, Wolanczyk T. Changes in emotional and behavioral problems between 2000 and 2011 among 16-year-old polish children: a cross-sectional study. Child Psychiatry Hum Dev. 2018;49:75765. doi:10.1007/s10578-018-0791-y.

23. Easterlin RA. Lost in transition: Life satisfaction on the road to capitalism. J Econ Behav Organ. 2009;71:130-45. doi:10.1016/j.jebo.2009.04.003.

24. Inchley J, Currie D, Young T, Samdal O, Torsheim T, Augustson L, et al., editors. Growing up unequal: gender and socioeconomic differences in young people's health and well-being: Health Behaviour in School-Aged Children (HBSC) Study: international report from the 2013/2014 survey. Copenhagen, Denmark: World Health Organization Regional Office for Europe; 2016.

25. Jamnik MR, DiLalla LF. Health outcomes associated with internalizing problems in early childhood and adolescence. Front Psychol. 2019;10:60. doi:10.3389/fpsyg.2019.00060.

26. González-Carrasco M, Casas F, Malo S, Viñas F, Dinisman T. Changes with age in subjective wellbeing through the adolescent years: differences by gender. J Happiness Stud. 2017;18:63-88. doi:10.1007/s10902-016-9717-1.

27. Brun Sundblad GM, Saartok T, Engstrom LM. Prevalence and co-occurrence of self-rated pain and perceived health in school-children: age and gender differences. Eur J Pain. 2007;11:171-180. doi:10.1016/j.ejpain.2006.02.006.

28. HAUGLAND S, Wold B, Haughland S, Wold B. Subjective health complaints in adolescenceReliability and validity of survey methods. J Adolesc. 2001;24:611-624. doi:10.1006/jado.2000.0393.

29. Stikkelbroek Y, Bodden DH, Kleinjan M, Reijnders M, van Baar AL. Adolescent depression and negative life events, the mediating role of cognitive emotion regulation. PLoS One. 2016;11:e0161062. doi:10.1371/journal.pone.0161062. 
30. Lester L, Cross D. The relationship between school climate and mental and emotional wellbeing over the transition from primary to secondary school. Psychol Well-Being. 2015;5:9. doi:10.1186/s13612015-0037-8.

31. Williams SG, Langhinrichsen-Rohling J, Wornell C, Finnegan H. Adolescents transitioning to high school: sex differences in bullying victimization associated with depressive symptoms, suicide ideation, and suicide attempts. J Sch Nurs. 2017;33:467-479. doi:10.1177/1059840516686840.

32. Mustanski B, Andrews R, Puckett JA. The effects of cumulative victimization on mental health among lesbian, gay, bisexual, and transgender adolescents and young adults. Am J Public Health. 2016;106:527-533. doi:10.2105/AJPH.2015.302976.

33. Seiffge-Krenke I. From parents to romantic partners in a globalized world: coping with relationship stress in adolescents from 20 nations. Adolesc Psychiatry. 2015;5:12-21. doi: $10.2174 / 221067660501150427111604$

34. Ravens-Sieberer U, Wille N, Erhart M, Nickel J, Richter M. Socioeconomic inequalities in mental health among adolescents in Europe. In: WHO, editor. Social cohesion for mental well-being among adolescents. Copenhagen: WHO Regional Office for Europe; 2008. p. 26-42.

http://www.euro.who.int/_data/assets/pdf_file/0005/84623/E91921.pdf.

35. Geckova AM, van Dijk JP, Zezula I, Tunistra J, Groothoff JW, Post D. Socio-economic differences in health among Slovak adolescents. Soz- Präventivmedizin. 2004;49:26-35. doi:10.1007/s00038-0032050-6.

36. Ravens-Sieberer U, Torsheim T, Hetland J, Vollebergh W, Cavallo F, Jericek H, et al. Subjective health, symptom load and quality of life of children and adolescents in Europe. Int J Public Health. 2009;54:151-159. doi:10.1007/s00038-009-5406-8.

37. von Rueden U, Gosch A, Rajmil L, Bisegger C, Ravens-Sieberer U. Socioeconomic determinants of health related quality of life in childhood and adolescence: results from a European study. J Epidemiol Community Health. 2006;60:130-135. doi:10.1136/jech.2005.039792.

38. Elgar FJ, Pförtner T-K, Moor I, De Clercq B, Stevens GWJM, Currie C. Socioeconomic inequalities in adolescent health 2002-2010: a time-series analysis of 34 countries participating in the Health Behaviour in School-aged Children study. Lancet Lond Engl. 2015;385:2088-95. doi: 10.1016/S0140-6736(14)61460-4

39. Moor I, Richter M, Ravens-Sieberer U, Ottová-Jordan V, Elgar FJ, Pförtner T-K. Trends in social inequalities in adolescent health complaints from 1994 to 2010 in Europe, North America and Israel: The HBSC study. Eur J Public Health. 2015;25 suppl_2:57-60. doi:10.1093/eurpub/ckv028.

40. Inchley J, Currie D, Cosma A, Samdal O. Health Behaviour in School-aged Children (HBSC) study protocol: background, methodology and mandatory items for the 2017/18 survey. St Andrews: CAHRU; 2018.

41. Sigmund E, Bad'ura P, Sigmundová D, Csémy L, Kalman M. Methodological Aspects of Trend Studies and Development of the HBSC Study in the Czech Republic. Cent Eur J Public Health. 2017;25 Supplement 1:S4-9. doi:10.21101/cejph.a4953. 
42. Šmigelskas K, Lukoševičiūtè J, Vaičiūnas T, Mozūraitytè K, Ivanavičiūtè U, Milevičiūtè I, et al. Measurement of Health and social behaviors in schoolchildren: Randomized study comparing paper versus electronic mode. Slov J Public Health. 2019;58:1-10. doi:10.2478/sjph-2019-0001.

43. Dey MA, Jorm FA, Mackinnon J. Cross-sectional time trends in psychological and somatic health complaints among adolescents: a structural equation modelling analysis of "Health Behaviour in School-aged Children" data from Switzerland. Soc Psychiatry Psychiatr Epidemiol. 2015;50:118998. doi:10.1007/s00127-015-1040-3.

44. Cantril H. The pattern of human concern. Rutgers University Press.; 1965.

45. Levin KA, Currie C. Reliability and Validity of an Adapted Version of the Cantril Ladder for Use with Adolescent Samples. Soc Indic Res. 2014;119:1047-63. doi:10.1007/s11205-013-0507-4.

46. Currie $C$, Molcho M, Boyce W, Holstein B, Torsheim T, Richter M. Researching health inequalities in adolescents: The development of the Health Behaviour in School-Aged Children (HBSC) Family Affluence Scale. Soc Sci Med. 2008;66:1429-36. doi:10.1016/j.socscimed.2007.11.024.

47. Maughan B, Collishaw S, Meltzer H, Goodman R. Recent trends in UK child and adolescent mental health. Soc Psychiatry Psychiatr Epidemiol. 2008;43:305-310. doi:10.1007/s00127-008-0310-8.

48. Cavallo F, Dalmasso P, Ottova-Jordan V, Brooks F, Mazur J, Valimaa R, et al. Trends in self-rated health in European and North-American adolescents from 2002 to 2010 in 32 countries. Eur J Public Health. 2015;25 Suppl 2:13-15. doi:10.1093/eurpub/ckv011.

49. Proctor C, Linley PA, Maltby J. Life Satisfaction. In: Levesque RJR, editor. Encyclopedia of Adolescence. Cham: Springer International Publishing; 2017. p. 1-12. doi:10.1007/978-3-319-321325_125-2.

50. Ryff CD, Keyes CL. The structure of psychological well-being revisited. J Pers Soc Psychol. 1995;69:719-27.

51. Van Droogenbroeck F, Spruyt B, Keppens G. Gender differences in mental health problems among adolescents and the role of social support: results from the Belgian health interview surveys 2008 and 2013. BMC Psychiatry. 2018;18:6. doi:10.1186/s12888-018-1591-4.

52. Fischer AH. Sex Differences in Emotionality: Fact or Stereotype? Fem Psychol. 1993;3:303-318. doi:10.1177/0959353593033002.

53. Whitehead RD, Cosma A, Cecil J, Currie C, Currie D, Neville F, et al. Trends in the perceived body size of adolescent males and females in Scotland, 1990-2014: changing associations with mental wellbeing. Int J Public Health. 2018;63:69-80. doi:10.1007/s00038-017-0997-y.

54. van Wijk CMTG, Kolk AM. Sex differences in physical symptoms: The contribution of symptom perception theory. Soc Sci Med. 1997;45:231-246. doi:https://doi.org/10.1016/S02779536(96)00340-1.

55. Wiklund M, Malmgren-Olsson E-B, Öhman A, Bergström E, Fjellman-Wiklund A. Subjective health complaints in older adolescents are related to perceived stress, anxiety and gender - a crosssectional school study in Northern Sweden. BMC Public Health. 2012;12:993. doi:10.1186/14712458-12-993. 
56. OECD Income Distribution Database (IDD): Gini, poverty, income, Methods and Concepts - OECD. https://www.oecd.org/social/income-distribution-database.htm. Accessed 18 Feb 2020.

57. Czech Statistical Office (2018). Czech Republic in Figures - 2018. https://www.czso.cz/csu/czso/czech-republic-in-figures-2018. Accessed 18 Feb 2020.

\section{Figures}
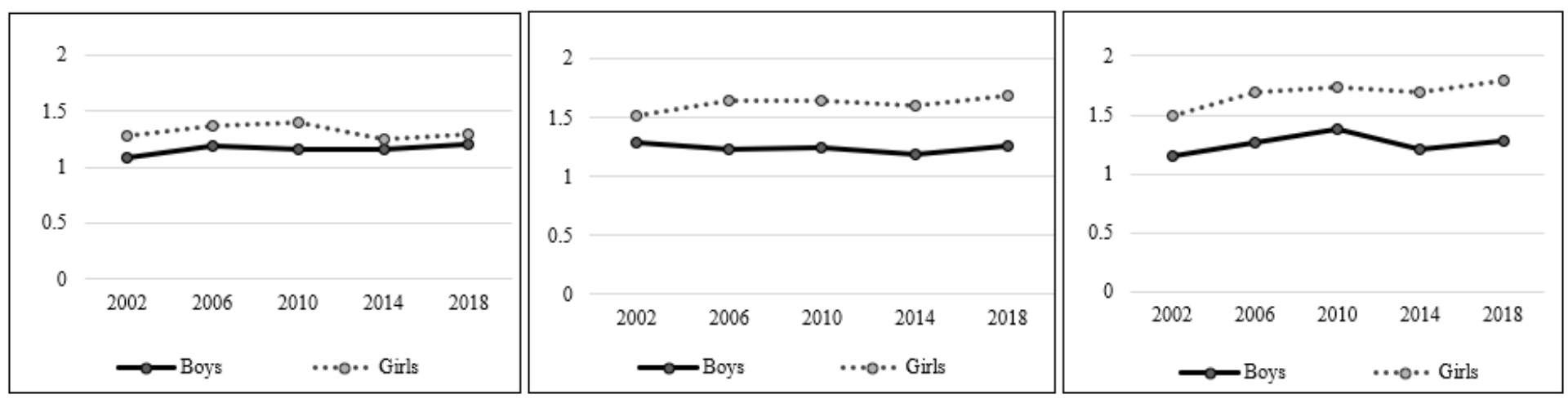

Figure 1

1a-1c. Trends over time in psychological complaints by gender and age (Figure1a: 11-year olds; Figure 1b: 13-year olds, Figure 1c:15-year olds) Legend: OY: Mean Psychological Complaints OX: HBSC Survey Year 